\title{
Risk factors associated with nosocomial infections in the Neonatal Intensive Care Unit at Mahatma Gandhi Memorial hospital between 2014 and 2015
}

\author{
Sharita Rameshwarnath* and Saloshni Naidoo iD \\ Discipline of Public Health Medicine, School of Nursing and Public Health, University of KwaZulu-Natal, Durban, South Africa \\ *Corresponding author, email: Sharita.Rameshwarnath@kznhealth.gov.za
}

Background: Nosocomial infections are one of the main causes of neonatal morbidity and mortality in low- and middle-income countries. The neonatal intensive care unit is a suitable environment for disseminating infections. The aim of this study was to identify risk factors associated with having a nosocomial infection in the neonatal intensive care unit at Mahatma Gandhi Memorial hospital between 2014 and 2015.

Methods: An observational, analytical case-control study was conducted at the neonatal intensive care unit at Mahatma Gandhi Memorial hospital in 2017 following ethical approval (BE336/16). A retrospective review of medical records for a sample size of 144 cases and 144 matched controls from 2014 to 2015 was analysed. Descriptive statistics were presented and multivariate conditional logistic regression was used to determine associations between the independent variables and having a nosocomial infection.

Results: A total of 144 neonates developed nosocomial infections as proven by positive cultures with Klebsiella pneumoniae being most frequent ( $n=60 ; 41.67 \%)$. On multivariate logistic regression analysis, multiple deliveries, low birth weight, respiratory distress, prematurity, neonatal jaundice, hyaline membrane disease, the use of total parenteral nutrition, blood transfusion and surfactant administration, immediate use of oxygen and intravenous fluid and central line insertion were significantly associated with having a nosocomial infection $(p \leq 0.001)$.

Conclusion: Neonatal-related factors and treatment modalities were identified as factors that increased the risk for nosocomial infections. A review of treatment modalities and related infection prevention and control in neonatal management are the key to prevention, early detection and management of nosocomial infections.

Keywords: bloodstream infections, demographic profile of neonates, infection control, neonatal sepsis/infections

\section{Introduction}

Neonates are a vulnerable group in the population, most prone to infections. ${ }^{1}$ Globally there were 7.6 million deaths in children aged below five years in 2010; 64\% (4.9 million) were attributed to infectious causes and 40\% (3.1 million) occurred in neonates. ${ }^{2}$ Nosocomial infection contributes significantly to neonatal morbidity and mortality, longer hospitalisation and an increased cost of treatment globally and particularly in low- and middleincome countries. ${ }^{3,4}$ In sub-Saharan Africa, 1.2 million babies die before they reach 28 days of life and the majority of the deaths are due to nosocomial infections. ${ }^{5}$ In South Africa, more than 40000 children died in 2014 and neonate and infant deaths accounted for the larger percentage of deaths among those below five years old. ${ }^{6}$

Participants' characteristics and treatment modalities play a vital role in susceptibility to and outcomes of nosocomial infections. ${ }^{7}$ Many studies conducted in high-income, middle- and lowincome countries have identified preterm birth, prolonged mechanical ventilation and the use of third-generation cephalosporin as the main risk factors for extended spectrum beta-lactamase (ESBL) producing Klebsiella pneumoniae infections. ${ }^{8,9}$ An increase in carbapenem-resistant strains, especially in late onset Klebsiella pneumoniae, has resulted in a significant increase in neonatal deaths and limited antibiotic choices. ${ }^{10}$

A study conducted in Egypt in 2014 showed that the risk of nosocomial infections increases as the birth weight of the neonate decreases and the need for invasive procedures increases. $^{3}$
Premature or low birth weight neonates are under profound physiological stressors. Work conducted in Soweto showed that the risk factors associated with early onset nosocomial infections were preterm delivery (adjusted relative risk $[\mathrm{aRR}]=2.6 ; 95 \%$ confidence interval [Cl] 1.4-4.8) and low birth weight (aRR =6.5; 95\% Cl 2.4-17.3.11 Meconium stained amniotic fluid was associated with late onset of sepsis (aRR $=2.4$ and $95 \% \mathrm{Cl} 1.1$ 5.0). ${ }^{11}$ Christina et al. concluded that premature infants were more susceptible to hospital-acquired infections as opposed to those with a normal gestational age (OR 4.45, 95\% Cl 2.04-9.72). ${ }^{12}$ Highly advanced improvements in diagnostic and therapeutic management have increased the incidence of nosocomial infections..$^{3,13}$ Newborns are susceptible to infections as they lack efficient structural barriers, protective endogenous microbial flora and a mature immune system. ${ }^{14}$

Notably, the increased use of antibiotics has caused the emergence of resistant bacterial strains like Gentamycin-resistant Klebsiella species, third-generation cephalosporin-resistant gram negative organisms and methicillin-resistant Staphylococcus aureus. ${ }^{15}$ Health-care associated infections represent a significant factor for neurological complications and death, which is aggravated by an inevitable prolonged hospital stay. ${ }^{16}$

An estimated $85 \%$ of all neonatal intensive care units (NICU) harbour nosocomial pathogens due to transgressions of infection prevention and control (IPC) principles. ${ }^{17}$ Transmission via hands may promote endemic strains of pathogenic organisms that remain viable for a period of time. ${ }^{16}$ Neonates in NICU are exposed to specific and non-specific risk factors which increase the risk of bacterial and fungal sepsis, ${ }^{16}$ including the recurrent 
use of broad-spectrum antimicrobial drugs, parental nutrition, acid inhibitor and steroids. Environmental risk factors associated with the transmission of infections are significant and related to seasonal changes. ${ }^{18}$

A study done by Yamani (2013) showed that catheter-associated blood stream infection increased $(95 \% \mathrm{Cl}$ of $13.7-23.8)$ due to transgressions in IPC principles during and after insertion of catheters. ${ }^{19}$ Ventilator-associated pneumonia (VAP) is noted to be the second most common hospital-acquired infection due to poor compliance with IPC principles and practices in the management of neonates. ${ }^{20}$ Risk factors that result in an increased incidence of nosocomial infections are contaminated water, poor physical design of NICUs, overcrowding of neonates and staff shortages resulting in an inadequate nurse-patient ratio, as well as poorly implemented antibiotic policy and infection prevention and control programmes. ${ }^{17}$

A shortage of health-care workers is an important constraint in sub-Saharan Africa where more than $24 \%$ of the global burden of disease occurs and where only $3 \%$ of the world's health-care workers are employed. ${ }^{5}$ A quantitative analysis including 26 studies was conducted by Stapleton et al. (2016) identified understaffing identified as the main risk factor for outbreaks, as well as horizontal spreading of infection from neonates admitted with pathogens. ${ }^{21}$

A well-documented outbreak claimed the lives of 21 neonates in 2005 in Mahatma Gandhi Memorial hospital (MGMH), in eThekwini, KwaZulu-Natal. Twenty-six babies had positive blood cultures for mainly pathogen Klebsiella pneumoniae, but also for Klebsiella oxytoca. ${ }^{22}$ This outbreak was a health systems failure. ${ }^{7}$ The outbreak investigation team noted that gentamycin-resistant ESBL producing Klebsiella pneumoniae was present in intravenous medication (vamin glucose) and formula feeds, which were used for multiple administrations to all of the babies. ${ }^{7,23}$ The other findings were that Klebsiella pneumoniae was present on the hands of $10 \%$ of the staff, the nursery was overcrowded, and the unit was under-equipped and under-staffed. ${ }^{7,22}$ All of these lead to transgressions and poor adherence to IPC principles and practices. Thus the aim of this study was to identify risk factors associated with having a nosocomial infection in the NICU at MGMH between 2014 and 2015. The specific objectives were to describe the demographic and clinical profile and to identify associations between the demographic profiles, clinical factors, health system factors and having a nosocomial infection among neonates admitted to the NICU at MGMH between 2014 and 2015.

\section{Methods}

\section{Study design and population}

An observational, analytical case-control study was conducted at the NICU at MGMH in 2017. This is a 388-bed hospital with a 35bed NICU that provides a regional level of care to the population in the northern part of the eThekwini municipality in KwaZuluNatal and serves as the referral hospital for a district hospital, and for rural and urban primary health-care centres.

All neonates who were admitted and remained for at least $48 \mathrm{~h}$ in the period January 2014 to December 2015 were included in the study. We excluded any neonate that died, was transferred to another hospital or discharged within $48 \mathrm{~h}$ of admission or if the laboratory results were missing.
A case was defined as a neonate who developed a nosocomial infection $48 \mathrm{~h}$ post admission which was confirmed by a positive culture from a sterile site of blood, urine or cerebrospinal fluid. A control was defined as a neonate with a negative culture from a sterile site of blood, urine or cerebrospinal fluid during his/her stay in NICU.

\section{Sample size}

A total sample of 266 with 133 cases and 133 matched controls was required to detect a minimum odds ratio of two assuming a baseline prevalence exposure of $40 \%$ among the control group, with $80 \%$ power and $95 \%$ confidence. There were a total of 4636 neonatal admissions for the period of January 2014 to December 2015 in the NICU at MGMH. The admission and separation registers in the NICU assisted the researcher in the matching of controls to cases. The positive laboratory results and IPC registers were used to confirm all cases. A total of 144 cases were identified for the study period and matched with controls for gender and the date of admission to the NICU.

\section{Data collection and tools}

Data were extracted from participants' medical records and included maternal and neonate demographic characteristics, neonate anthropometric measurements, clinical condition (length of stay and in-hospital mortality), sources of specimen, date of admission and collection, recent antibiotic therapy, therapeutic interventions (ventilation, endotracheal tube continuous positive airway pressure [CPAP], central venous catheters, Foley's catheters and nasogastric tubes), referral information and general care of patients. Data for independent variables were collected prior and up to the identification of a positive culture. No information on management following the diagnosis was collected as the aim was to establish risk factors associated with nosocomial infections in the NICU.

The researcher retrieved the participants' records using the hospital information system, laboratory information system and the registers available in the NICU. Data were captured in Excel ${ }^{\oplus}$ (Microsoft Corp, Redmond, WA, USA) and kept confidential in password-protected folders with each participant allocated a unique study identity. All completed data sheets were stored in a lockable cupboard for further reference and safe keeping. All electronic data were saved in a password-protected file.

\section{Data analysis}

Data were analysed in Stata ${ }^{\circledR} 13.0$ (StataCorp.2013. Stata Statistical Software: Release 13; StataCorp LP, College Station, TX, USA). Univariate analysis of variables was expressed as frequencies for categorical variables and medians with ranges were presented for continuous variables. Chi-square was used to test for the associations between categorical independent variables and the dependent variable under study. Multivariable analysis was conducted using conditional logistic regression (accounting for the matching) to test for associations between the independent variables and dependent variable under study. The level of significance was accepted as 0.05 ( $\alpha=$ 0.05).

This study was approved by the Biomedical Research Ethics Committee at the University of KwaZulu-Natal, the KwaZuluNatal Provincial Department of Health and the medical manager of the facility (BE336/16). 


\section{Results}

There were 144 neonates that developed a nosocomial infection that was confirmed by positive culture between 2014 and 2015 . The majority of the isolated bacteria were Klebsiella pneumoniae ( $n=60,41.67 \%)$, Staphylococcus aureus $(n=29,20.14 \%)$ and Acinetobacter baumanni $(n=21,14.58 \%)$.

\section{Maternal demographic profiles}

There was no significant difference in median age between case mothers (median $=23.5$ years; range: $17-42$ years) and control mothers (median $=24.0$ years; range: $13-41$ years) $(p=0.786)$. Significantly more case mothers $(n=10 ; 6.94 \%)$ were Wasserman's reaction (WR) positive compared with control mothers $(n=1$; $0.69 \%),(p=0.05)$ and $(n=12 ; 8.33 \%)$ were significantly more likely to have had multiple deliveries as compared with control mothers $(n=3 ; 2.08 \%)(p=0.017)$. A significant number of control mothers $(n=36 ; 25 \%)$ reported having prolonged rupture of membranes as compared with case mothers ( $n=10 ; 6.94 \%)$, $(p<0.001)$. Of the 144 cases, $106(73.61 \%)$ were born in the facility while 119 (82.64\%) controls were born in the facility (Table 1).

\section{Neonatal demographics profiles}

There was a significant difference in the median birth weight between case neonates (median $=1777.14$ grams; range: 1644.89-1909.39) and control neonates (median $=2438.26$ grams; range: 2298.97-2577.56), ( $p<0.001)$. There was a significant difference in median head circumference $(p<0.001)$ and median height $(p=0.003)$ between case neonates and control neonates (Table 2).

Control neonates had a significantly longer gestational age than case neonates $(p \leq 0.001)$. Apgar scores below seven at one minute was non-significant for case neonates $(n=107 ; 81.68 \%)$ when compared to control neonates ( $n=97 ; 71.85 \%),(p=0.058)$. Significantly more case neonates presented with central nervous system abnormalities $(p=0.038)$ and respiratory distress compared with control neonates $(p<0.001)$. Prematurity $(p<$ $0.001)$, birth asphyxia $(p<0.001)$ and neonatal jaundice $(p<$ 0.001 ) were significantly more common among case neonates opposed to control neonates (Table 2).

\section{Immediate management of neonates}

There was significantly more oxygen administered at birth to case neonates $(n=117 ; 81.25 \%)$ than to control neonates $(n=85$; $56.94 \%),(p<0.001)$. Suctioning occurred in significantly more case neonates $(n=113 ; 78.47 \%)$ than control neonates $(n=93$; $64.58 \%),(p=0.009)$. Significantly more case neonates $(n=128$; $88.89 \%$ ) had insertion of an intravenous line and administration of intravenous fluids as compared with control neonates $(n=90$; $62.50 \%),(p<0.001)$. Significantly more control neonates $(n=79$; $54.86 \%)$ compared with case neonates $(n=27 ; 18.75 \%)$ received feeds $(p<0.001)$ (see Table 2 ).

\section{Therapeutic interventions}

Marginally significantly more control $(n=144 ; 100 \%)$ than case neonates ( $n=139 ; 97.20 \%$ ) received antibiotics on admission ( $p$ $=0.043$ ). There was a significantly greater use of nasogastric tubes and central venous catheters in case ( $83.33 \%$ and $67.36 \%)$ compared with control neonates $(36.11 \%$ and $20.83 \%)$, $(p \leq 0.001)$. Surfactant, blood transfusion and total parenteral nutrition (TPN) administration was significantly more frequent in case neonates $(49.31,40.97$ and $29.86 \%$ ) compared with control
Table 1: Maternal demographic profiles of hospitalised neonates in NICU from 2014 to $2015(\boldsymbol{n}=288)$

\begin{tabular}{|c|c|c|c|}
\hline Variables & $\begin{array}{l}\text { Case mothers } \\
\qquad(n=144)\end{array}$ & $\begin{array}{l}\text { Control mothers } \\
(n=144)\end{array}$ & $p$-value \\
\hline $\begin{array}{l}\text { Maternal age in } \\
\text { years (median; } \\
\text { range) }\end{array}$ & $23.5(17-42)$ & $24(13-41)$ & 0.78 \\
\hline \multicolumn{4}{|l|}{ Mode of delivery: } \\
\hline Caesarean section & $59(40.97)$ & $49(34.03)$ & 0.224 \\
\hline $\begin{array}{l}\text { Normal vertex } \\
\text { delivery }\end{array}$ & $85(59.03)$ & $95(65.97)$ & \\
\hline \multicolumn{4}{|l|}{$\begin{array}{l}\text { Prolonged rupture } \\
\text { of membranes: }\end{array}$} \\
\hline Yes & $10(6.94)$ & $36(25)$ & $<0.001$ \\
\hline no & $134(93.06)$ & $108(75)$ & \\
\hline \multicolumn{4}{|l|}{ Booking status } \\
\hline Booked & $132(92.96)$ & $134(93.06)$ & 0.97 \\
\hline Unbooked & $12(7.04)$ & $10(6.94)$ & \\
\hline \multicolumn{4}{|l|}{ Perinatal risks: } \\
\hline Yes & $45(31.47)$ & $42(29.58)$ & 0.729 \\
\hline No & $99(68.53)$ & $102(70.42)$ & \\
\hline \multicolumn{4}{|l|}{$\begin{array}{l}\text { Human immunode- } \\
\text { ficiency virus: }\end{array}$} \\
\hline Positive & $66(46.81)$ & $71(49.3)$ & 0.591 \\
\hline Negative & $78(53.19)$ & $73(50.7)$ & \\
\hline \multicolumn{4}{|l|}{$\begin{array}{l}\text { Wasserman's } \\
\text { reaction: }\end{array}$} \\
\hline Positive & $10(6.94)$ & $1(0.69)$ & \\
\hline Negative & $129(92.81)$ & $143(99.31)$ & 0.005 \\
\hline \multicolumn{4}{|l|}{ Rhesus: } \\
\hline Positive & $136(97.14)$ & $141(97.92)$ & 0.674 \\
\hline Negative & $8(2.86)$ & $3(2.08)$ & \\
\hline \multicolumn{4}{|l|}{ Place of delivery: } \\
\hline $\begin{array}{l}\text { Born at another } \\
\text { facility }\end{array}$ & $38(26.39)$ & $25(17.36)$ & Ref. \\
\hline $\begin{array}{l}\text { Born at Mahatma } \\
\text { Gandhi Memorial } \\
\text { hospital }\end{array}$ & $106(73.61)$ & $119(82.64)$ & 0.064 \\
\hline Born before arrival & $11(7.64)$ & $9(6.25)$ & 0.643 \\
\hline \multicolumn{4}{|l|}{ Multiple deliveries: } \\
\hline Yes & $12(8.33)$ & $3(2.08)$ & 0.017 \\
\hline No & $132(91.66)$ & 141 (97.92) & \\
\hline
\end{tabular}

Note: Ref. $=$ reference.

neonates $(8.33,4.86$ and $5.56 \%),(p \leq 0.001)$. The other therapeutic interventions that were associated with case neonates were 
Table 2: Neonatal demographic profiles of hospitalised neonates in NICU from 2014 to $2015(\boldsymbol{n}=288)$

\begin{tabular}{|c|c|c|c|}
\hline Variables & Case neonates $(n=144) \%$ & Control neonates $(n=144) \%$ & $p$-value \\
\hline Weight in grams (median; range) & 1777.14 (1644.89-1909.39) & 2438.26 (2298.97-2577.56) & \\
\hline$>1000$ & $17(11.80)$ & $5(3.47)$ & Ref. \\
\hline $1001-1500$ & $60(41.66)$ & $18(12.5)$ & 0.973 \\
\hline $1501-2000$ & $20(13.88)$ & $34(23.61)$ & 0.003 \\
\hline $2001-2500$ & $23(15.97)$ & $15(10.42)$ & 0.190 \\
\hline$\geq 2501$ & $24(16.67)$ & $72(50)$ & $<0.001$ \\
\hline $\begin{array}{l}\text { Head circumference in centimetres (median; } \\
\text { range) }\end{array}$ & $31(22-39)$ & $33(27-55)$ & $<0.001$ \\
\hline Height in centimetres (median; range) & $42(28-58)$ & $47(31-57)$ & 0.003 \\
\hline Pulse (median; range) & $155(100-197)$ & $156(100-190)$ & 0.968 \\
\hline Respiratory rate (median; range) & $60(45-87)$ & $60(50-73)$ & 0.045 \\
\hline \multicolumn{4}{|l|}{ Gestational age in weeks: } \\
\hline$<30$ & $53(36.8)$ & 19 (13.19) & Ref. \\
\hline $31-36$ & $63(43.75)$ & $64(44.44)$ & 0.001 \\
\hline$\geq 37$ & $28(19.44)$ & $61(42.36)$ & $<0.001$ \\
\hline \multicolumn{4}{|l|}{ Apgar 1 min: } \\
\hline $0-7$ & $107(81.68)$ & $97(71.85)$ & 0.058 \\
\hline $8-10$ & $24(18.32)$ & $38(28.15)$ & \\
\hline \multicolumn{4}{|l|}{ Apgar 5 min: } \\
\hline $0-7$ & $29(22.14)$ & $16(11.85)$ & 0.025 \\
\hline $8-10$ & $102(77.86)$ & 119 (88.15) & \\
\hline \multicolumn{4}{|l|}{ Pathologies: } \\
\hline Cardiovascular abnormalities (yes) & $14(9.72)$ & 0 & $<0.001$ \\
\hline Central nervous system abnormalities (yes) & $30(20.83)$ & $17(11.81)$ & 0.038 \\
\hline Respiratory distress (RDS) (yes) & $114(79.2)$ & $68(47.2)$ & $<0.001$ \\
\hline Prematurity (yes) & $110(76.39)$ & $60(41.67)$ & $<0.001$ \\
\hline Birth asphyxia (yes) & $38(26.39)$ & $12(8.33)$ & $<0.001$ \\
\hline Seizures (yes) & $4(2.78)$ & $7(4.86)$ & 0.356 \\
\hline Neonatal jaundice (yes) & $96(66.67)$ & $29(20.14)$ & $<0.001$ \\
\hline Necrotising enterocolitis (yes) & $24(16.67)$ & 0 & \\
\hline \multicolumn{4}{|l|}{ Immediate management of neonates: } \\
\hline Oxygen (yes) & $117(81.25)$ & $82(56.94)$ & $<0.001$ \\
\hline Suction (yes) & $113(78.47)$ & $93(64.58)$ & 0.009 \\
\hline Feeds (yes) & $27(18.75)$ & $79(54.86)$ & $<0.001$ \\
\hline Fluids (yes) & $128(88.89)$ & $90(62.50)$ & $<0.001$ \\
\hline $\begin{array}{l}\text { Number of days of total parenteral nutrition } \\
\text { (median; range) }\end{array}$ & $0(0-29)$ & $0(0-13)$ & $<0.001$ \\
\hline Number of days on ventilator (median; range) & $0(0-70)$ & $0(0-7)$ & $<0.001$ \\
\hline $\begin{array}{l}\text { Number of days of umbilical catheter (median; } \\
\text { range) }\end{array}$ & $0(0-20)$ & $0(0-14)$ & $<0.001$ \\
\hline $\begin{array}{l}\text { Number of days in high-care/intensive-care unit } \\
\text { (median; range) }\end{array}$ & $3(0-81)$ & $2(0-13)$ & $<0.001$ \\
\hline
\end{tabular}

Note: Ref. $=$ reference.

ventilation ( $n=38 ; 33.33 \%),(p=0.001)$ and bi-level positive airway pressure (Bipap) $(n=35 ; 24.31 \%),(p=0.001)$. Intravenous lines not changed within $72 \mathrm{~h}$ were significantly associated with case neonates $(p \leq 0.001)$ (Table 3 ). 
Table 3: Therapeutic interventions associated with the occurrence of nosocomial infection among hospitalised neonates from 2014 to 2015 $(n=288)$

\begin{tabular}{|c|c|c|c|}
\hline $\begin{array}{l}\text { Therapeutic } \\
\text { intervention }\end{array}$ & $\begin{array}{l}\text { Case neonates } \\
\qquad(n=144)\end{array}$ & $\begin{array}{l}\text { Control neonates } \\
\qquad(n=144)\end{array}$ & $p$-value \\
\hline $\begin{array}{l}\text { Total parenteral } \\
\text { nutrition (yes) }\end{array}$ & $43(29.86)$ & $8(5.56)$ & $<0.001$ \\
\hline $\begin{array}{l}\text { Antibiotic at admis- } \\
\text { sion (yes) }\end{array}$ & $139(97.20)$ & $144(100)$ & 0.043 \\
\hline Surfactant (yes) & 71 (49.31) & $12(8.33)$ & $<0.001$ \\
\hline $\begin{array}{l}\text { Blood transfusion } \\
\text { (yes) }\end{array}$ & $59(40.97)$ & $7(4.86)$ & $<0.001$ \\
\hline $\begin{array}{l}\text { Lumbar puncture } \\
\text { (yes) }\end{array}$ & $16(11.11)$ & $6(4.20)$ & 0.028 \\
\hline Chest drain (yes) & $9(6.25)$ & $2(1.39)$ & 0.031 \\
\hline $\begin{array}{l}\text { Bi-level positive } \\
\text { airway pressure } \\
\text { (yes) }\end{array}$ & $35(24.31)$ & $6(4.170$ & $<0.001$ \\
\hline $\begin{array}{l}\text { Continuous posi- } \\
\text { tive airway pressure } \\
\text { (yes) }\end{array}$ & 20 (13.89) & $9(6.25)$ & 0.031 \\
\hline Ventilation (yes) & $48(33.33)$ & $20(13.89)$ & $<0.001$ \\
\hline $\begin{array}{l}\text { Nasogastric tube } \\
\text { (yes) }\end{array}$ & $120(83.33)$ & $52(36.110$ & $<0.001$ \\
\hline Peripheral line (yes) & $144(100)$ & $141(97.92)$ & 0.082 \\
\hline $\begin{array}{l}\text { Central venous } \\
\text { catheter (yes) }\end{array}$ & $97(67.36)$ & $30(20.83)$ & $<0.001$ \\
\hline $\begin{array}{l}\text { Endotracheal tube } \\
\text { changed (yes) }\end{array}$ & $20(66.67)$ & $4(16.67)$ & $<0.001$ \\
\hline $\begin{array}{l}\text { Intravenous line } \\
\text { changed } 72 \text { h (yes) }\end{array}$ & $5(3.19)$ & $2(1.39)$ & $<0.001$ \\
\hline $\begin{array}{l}\text { Intravenous fluid } \\
\text { changed } 24 \text { h (yes) }\end{array}$ & $5(3.79)$ & $1(1.05)$ & $<0.204$ \\
\hline $\begin{array}{l}\text { Umbilical catheter } \\
\text { changed 5-7 days } \\
\text { (yes) }\end{array}$ & $25(27.17)$ & $11(31.35)$ & 0.635 \\
\hline
\end{tabular}

\section{Multivariate analysis}

Case mothers were significantly more likely to have had multiple deliveries as compared with control mothers $(\mathrm{OR}=5.50 ; 95 \% \mathrm{Cl}$ 1.15-26.42). More case mothers were WR positive ( $O R=13.37$; $95 \% \mathrm{Cl} 1.24-144.44)$ than control mothers. Weighing more than 2.5 kilograms was protective against being a case neonate $(\mathrm{OR}=$ $0.07 ; 95 \% \mathrm{Cl} 0.01-0.39$ ). Neonatal jaundice was significantly associated with being a case neonate $(\mathrm{OR}=6.95$; $95 \% \mathrm{Cl}$ : $2.97-$ 16.27). Significantly associated with being a case are respiratory distress and prematurity $(\mathrm{OR}=3.15 ; 95 \% \mathrm{Cl} 1.46-6.79$ and $\mathrm{OR}=$ $4.55 ; 95 \% \mathrm{Cl} 2.064-10.023)$.

The risk of infection was higher in case neonates with the administration of TPN (OR $=9.41 ; 95 \% \mathrm{Cl} 1.70-52.06)$, surfactant $(\mathrm{OR}=10.97 ; 95 \% \mathrm{Cl} 4.75-25.34)$ and blood transfusion $(\mathrm{OR}=$ 9.40; 95\% Cl 2.39-37.00) (Table 4).

\section{Discussion}

Despite rigorous surveillance strategies, prophylactic processes and the development of new treatment options and life support techniques, nosocomial infection remains a major problem in many low- and middle-income countries.,24 This study in a regional hospital highlights the contribution of maternal and neonatal factors and neonatal management toward nosocomial infections in NICUs.

Significantly in this study more case mothers were WR positive compared with control mothers $(\mathrm{OR}=13.37 ; 95 \% \mathrm{Cl} 1.24-144.44)$; however, there are no identified studies that showed an association of nosocomial infection and WR. The neonate of a mother that is WR positive is at risk due to being immune compromised, which could lead to infection in the neonate.

Case mothers were significantly more likely to have multiple deliveries compared with control mothers $(\mathrm{OR}=5.50,95 \% \mathrm{Cl}$ 1.15-26.42). A study in Jeddah, by Albasri et al., showed that multiple births were associated with prematurity and low birth weight, ${ }^{25}$ which is associated with an increased risk for nosocomial infection. Interestingly a significant number of control mothers $(n=36 ; 25 \%)$ reported having prolonged rupture of membranes as compared with case mothers $(n=10$; $6.94 \%),(p<0.001)$. A study conducted by Doaa Mohammed et al. showed a seven times higher risk of nosocomial infection among neonates exposed to PROM. ${ }^{3}$ However, in this study this was not seen and may be attributed to the fact that neonates of the mothers with prolonged rupture of membranes received antibiotics as standard practice, protecting them against nosocomial infections.

In this study birth weight below $2500 \mathrm{~g}$ was shown to be a risk factor for acquiring nosocomial infections. Studies have identified birth weight as a persistent and independent predictor of nosocomial infection. ${ }^{3,4,26,27}$ Low birth weight newborns are susceptible to infections due to the lack of efficient structural barriers, protective endogenous microbial flora and a mature immune system, ${ }^{14}$ which was probably the case in this study.

Significantly associated with an increasing risk of infection in this study was a shorter gestational age. It has been shown that as the gestational age decreases, the risk of infection increases as a result of the neonate being either of a low birth weight or extremely low birth weight. This finding was supported by a study done in Italy by Auriti et al. in which it was documented that shorter gestational age rendered neonates more susceptible to nosocomial infections. ${ }^{28}$

In this study, an Apgar score of less than 7 at five minutes was identified as a significant predisposing factor acquiring a nosocomial infection $(p=0.025)$. A study in North Ethiopia by Destaalem Gebremedhin et al. (2016) reported that those who had an Apgar of less than 7 at one minute and five minutes were higher in case neonates than control neonates. ${ }^{29}$ The study showed that neonates with an Apgar of less than 7 at five minutes had a greater risk of acquiring nosocomial infection ( $A O R=68.9$; $95 \% \mathrm{Cl} 3.63,1307.90) .^{29}$

Respiratory distress with different levels of severity (79.2\%) ( $p<$ 0.001) was one of the clinical conditions associated with nosocomial infections. Studies have identified respiratory distress as a primary reason for admission to the NICU, but there was no direct association with nosocomial infection. ${ }^{3,30}$ However, neonates that were exposed to many therapeutic interventions were susceptible to nosocomial infections. ${ }^{3,30}$ 
Table 4: Multivariable analysis of the risk factors associated with nosocomial infections in the NICU at MGMH from 2014 to 2015 ( $\boldsymbol{n}=288$ )

\begin{tabular}{|c|c|c|c|c|}
\hline Risk factors & Case neonates $(n=144)$ & Control neonates $(n=144)$ & $p$-value & OR $(95 \% \mathrm{Cl})$ \\
\hline \multicolumn{5}{|l|}{ Maternal factors: } \\
\hline Wasserman's reaction & $10(6.94)$ & $1(0.69)$ & 0.005 & $13.37(1.24-144.44)$ \\
\hline Prolonged rupture of membranes & $10(6.94)$ & $36(25)$ & $<0.001$ & $0.33(0.15-0.73)$ \\
\hline Multiple deliveries & $12(8.33)$ & $3(2.08)$ & 0.017 & $5.50(1.15-26.42)$ \\
\hline \multicolumn{5}{|l|}{ Neonatal factors: } \\
\hline Apgar (1 min) 0-7 & $107(81.68)$ & $97(71.85)$ & 0.058 & $1.37(0.74-2.53)$ \\
\hline \multicolumn{5}{|l|}{ Weight in grams: } \\
\hline$>1000 \mathrm{~g}$ & $17(11.80)$ & $5(3.47)$ & Ref. & \\
\hline $1001-1500$ & $60(41.66)$ & $18(12.50$ & 0.686 & $1.30(0.37-4.63)$ \\
\hline $1501-2000$ & $20(13.88)$ & $34(23.61)$ & 0.003 & $0.09(0.02-0.45)$ \\
\hline $2001-2500$ & $23(15.97)$ & $15(10.42)$ & 0.472 & $0.56(0.12-2.70)$ \\
\hline$\geq 2501$ & $24(16.67)$ & $72(50)$ & $<0.001$ & $0.07(0.01-0.39)$ \\
\hline \multicolumn{5}{|l|}{ Gestational age in weeks: } \\
\hline$<30$ & $53(36.8)$ & $19(13.14)$ & Ref. & \\
\hline $30-36$ & $63(43.75)$ & $64(44.44)$ & 0.495 & $0.71(0.26-1.92)$ \\
\hline$\geq 37$ & $28(19.44)$ & $61(42.36)$ & 0.330 & $0.48(0.11-2.11)$ \\
\hline \multicolumn{5}{|l|}{ Pathologies: } \\
\hline Respiratory distress & $114(79.2)$ & $68(47.2)$ & 0.004 & $3.15(1.46-6.798)$ \\
\hline Prematurity & $110(76.39)$ & $60(41.67)$ & $<0.001$ & $4.55(2.064-10.02)$ \\
\hline Neonatal jaundice & $96(66.67)$ & $29(20.14)$ & $<0.001$ & $6.95(2.97-16.27)$ \\
\hline $\begin{array}{l}\text { Birth asphyxia/hyaline membrane } \\
\text { disease }\end{array}$ & $38(26.39)$ & $12(8.33)$ & $<0.001$ & $1.88(0.74-4.81)$ \\
\hline \multicolumn{5}{|l|}{ Immediate management: } \\
\hline Oxygen & $117(81.25)$ & $82(56.94)$ & 0.081 & $3.52(0.89-13.86)$ \\
\hline Suction & $113(78.47)$ & $93(64.58)$ & 0.072 & $0.29(0.08-1.08)$ \\
\hline Feeds & 27 (18.75) & $79(54.86)$ & 0.002 & $0.20(0.08-0.52)$ \\
\hline Fluids & $128(88.89)$ & $90(62.50)$ & 0.071 & $1.26(0.48-3.32)$ \\
\hline \multicolumn{5}{|l|}{ Therapeutic interventions: } \\
\hline $\begin{array}{l}\text { Bi-level positive airway pressure } \\
\text { use }\end{array}$ & $35(24.31)$ & $6(4.17)$ & $<0.001$ & $3.30(0.99-10.93)$ \\
\hline Ventilation & $48(33.33)$ & $20(13.89)$ & $<0.001$ & $4.18(0.86-20.30)$ \\
\hline Surfactant & $71(49.31$ & $12(8.33)$ & $<0.001$ & $10.97(4.75-25.34)$ \\
\hline Blood transfusion & $59(40.97)$ & $7(4.86)$ & $<0.001$ & $9.40(2.39-37.00)$ \\
\hline Total parenteral nutrition & $43(29.86)$ & $8(5.56)$ & $<0.001$ & $9.41(1.70-52.06)$ \\
\hline Central line & 97 (67.36) & $30(20.83)$ & $<0.001$ & $1.75(0.73-4.23)$ \\
\hline
\end{tabular}

Note: Ref. $=$

Prematurity was identified as a risk for infection in this study ( $p<$ 0.001 ), which is similar to the findings by Polin et al. ${ }^{4,31}$ It has been suggested that the most effective strategy to reduce nosocomial infection is to reduce the size of the most susceptible population in NICU. ${ }^{31}$ Christina et al. concluded that premature neonates were more susceptible to developing hospital infection as opposed to neonates of normal gestational age. ${ }^{12}$

Birth asphyxia was the other significant risk factor associated with infection in this study $(p<0.001)$. Leal et al. (2012) documented factors associated with risk of infections as birth asphyxia and multiple pregnancies, the former also associated with poor outcomes. ${ }^{27}$

It is well known that advances in diagnostic and therapeutic management have resulted in significant improvements in neonatal survival ${ }^{3,4}$ but these can place neonates at a significantly higher risk of acquiring nosocomial infections. ${ }^{3,4}$ In this study, the exposure to mechanical ventilation and Bipap independently suggested an increased risk for nosocomial infections but the confidence interval included no one (OR 4.18; C1 0.86-20.30, and OR 3.30; Cl 0.99-10.93). In the study conducted by Yadav et al. in 
Nepal, mechanical ventilation was identified as an independent risk factor for nosocomial infections (OR $=84 ; 95 \% \mathrm{Cl} 8.899$ 792.925). ${ }^{4}$ Neonates are susceptible to nosocomial infections due to exposure to invasive procedures, which is aggravated by the immunological immaturity of the neonates. ${ }^{4}$

Other significant risk factors in this study were administration of TPN, blood transfusion and surfactant. Other studies also support these findings. ${ }^{12,17}$ Similarly, studies in different countries confirmed that neonates that were exposed to TPN had a higher risk of acquiring nosocomial infection $(p<0.001) .^{32,33}$

\section{Limitations}

There were some limitations in our study. The retrospective nature of collection does not represent the most rigorous approach to collecting clinical assessment and management data. The lack of information on reporting on clinical assessment and management is a bias that limits the interpretation of the results. There may be additional unmeasured variables associated with nosocomial infection such as the nurse-patient ratio per day, which was not available in this study due to poor record keeping.

The results cannot be generalised as they represent a NICU in one regional hospital. The results are unit specific to $M G M H$. Information bias associated with retrospective studies revolved around abstracting the appropriate data using the designed tool. The missing data affect the data-set thus introducing a nondifferential measurement bias. The number of missing files was high $(n=17 ; 10.55 \%)$. All files for study subjects were managed by the hospital information system. Files are kept in several sites in the institution due to a shortage of an archive and space. Therefore the sample size was limited to the available files with positive cultures. However, the risk factors that were identified should remain significant and should not be affected by the sample size.

Data on health-care worker ( $\mathrm{HCW}$ ) practices was collected but could not be used as all the indicators in the tool were ticked twice a day as completed.

\section{Conclusion}

There were various risk factors associated with an increased risk of acquiring nosocomial infections in the NICU. In this study low birth weight, gestational age $<36$ weeks and an Apgar score of less than 7 at five minutes were identified as neonatal factors associated with a nosocomial infection. These findings coincide with the results of previous studies that reported an increase in nosocomial infection among low birth weight neonates and gestational age less than 36 weeks. ${ }^{12,34}$

Prematurity and multiple therapies are significant risk factors in this study as the neonates are immune compromised. ${ }^{34}$ Respiratory distress and birth asphyxia was identified as a significant risk factor associated with nosocomial infection. The most significant maternal association was multiple deliveries.

The present study also showed the therapeutic interventions of blood transfusion, surfactant and TPN as significant risk factors associated with nosocomial infections. Rigorous IPC measures during neonatal management are the key to prevention, early detection and management of nosocomial infections. The multidisciplinary team must be able to implement an excellent surveillance system that improves record keeping, allowing identification of risk factors, and contributes towards implementing strategies to reduce the nosocomial infection rate.
Funding - No funding available.

Disclosure statement - No potential conflict of interest was reported by the authors.

\section{ORCID}

Saloshni Naidoo (iD http://orcid.org/0000-0002-8844-0160

\section{References}

1. Ballot DE, Nana T, Sriruttan C, et al. Bacterial bloodstream infections in neonates in a developing country. ISRN Pediatr. 2012;2012.

2. Liu L, Johnson HL, Cousens $\mathrm{S}$, et al. Global, regional, and national causes of child mortality: an updated systematic analysis for 2010 with time trends since 2000. Lancet. 2012;379(9832):2151-2161. https://doi.org/10.1016/S0140-6736(12)60560-1

3. Mohammed D, El Seifi OS. Bacterial nosocomial infections in neonatal intensive care unit, Zagazig University Hospital, Egypt. Egypt Pediatr Assoc Gaz. 2014;62(3):72-79. https://doi.org/10.1016/j. epag.2014.10.001

4. Yadav S, Bhatta N, Kanodia P, et al. Risk factors for hospital acquired bloodstream infections in neonatal intensive care unit of BP Koirala Institute of Health Sciences, Nepal. Sri Lanka J Child Health. 2017;46(1):16-28.

5. Kinney MV, Kerber KJ, Black RE, et al. Sub-Saharan Africa's mothers, newborns, and children: where and why do they die? PLoS Med. 2010;7(6):e1000294. https://doi.org/10.1371/journal.pmed.1000294

6. Liu L, Hill K, Oza S, et al. Levels and causes of mortality under age five years. Reprod Matern Newborn Child Health. 2016:71.

7. Hlophe ST, McKerrow N. Hospital-acquired klebsiella pneumoniae infections in a paediatric intensive care unit. S Afr J Child Health. 2014;8(4):125-128. https://doi.org/10.7196/sajch.747

8. Huang $Y$, Zhuang $S$, Du M. Risk factors of nosocomial infection with extended-spectrum beta-lactamase-producing bacteria in a neonatal intensive care unit in China. Infect. 2007;35(5):339-345. https://doi.org/10.1007/s15010-007-6356-9

9. Huang SS, Septimus E, Kleinman K, Moody J, Hickok J, Avery TR, et al. Targeted versus universal decolonization to prevent ICU infection. N Engl J Med. 2013;368(24):2255-2265. https://doi.org/10.1056/ NEJMoa1207290

10. Saleem AF, Qamar FN, Shahzad H, et al. Trends in antibiotic susceptibility and incidence of late-onset Klebsiella pneumoniae neonatal sepsis over a six-year period in a neonatal intensive care unit in Karachi, Pakistan. Int J Infect Dis. 2013;17(11):e961-e5. https:// doi.org/10.1016/j.ijid.2013.04.007

11. Schrag SJ, Cutland CL, Zell ER, et al. Risk factors for neonatal sepsis and perinatal death among infants enrolled in the prevention of perinatal sepsis trial, Soweto, South Africa. Pediatr Infect Dis J. 2012;31(8):821826. https://doi.org/10.1097/INF.0b013e31825c4b5a

12. Christina N, Loanna P, George L, et al. Risk factors for nosocomial infections in neonatal intensive care units (NICU). Health Sci J. 2015;9(2):1-5.

13. Wattal C, Raveendran R, Goel N, Oberoi JK, Rao BK. Ecology of blood stream infection and antibiotic resistance in intensive care unit at a tertiary care hospital in North India. Braz J Infect Dis. 2014;18(3):245251. https://doi.org/10.1016/j.bjid.2013.07.010

14. Távora ACVCF, Castro AB, Militão MAM, et al. Risk factors for nosocomial infection in a brazilian neonatal intensive care unit. Braz J Infect Dis. 2008;12(1):75-79. https://doi.org/10.1590/S141386702008000100016

15. Fahmey SS. Early-onset sepsis in a neonatal intensive care unit in Beni Suef, Egypt: bacterial isolates and antibiotic resistance pattern. Korean J pediatr. 2013;56(8):332-337. https://doi.org/10.3345/ kjp.2013.56.8.332

16. Legeay C, Bourigault C, Lepelletier D, Zahar J. Prevention of healthcare-associated infections in neonates: room for improvement. J Hosp Infect. 2015;89(4):319-323. https://doi.org/10.1016/j. jhin.2015.02.003

17. Uwaezuoke $\mathrm{S}, \mathrm{Obu} \mathrm{H}$. Nosocomial infections in neonatal intensive care units: Cost-effective control strategies in resource-limited countries. Nigerian J Paediatr. 2013;40(2):125-132. 
18. Srivastava S, Shetty N. Healthcare-associated infections in neonatal units: lessons from contrasting worlds. J Hosp Infect. 2007;65(4):292306. https://doi.org/10.1016/j.jhin.2007.01.014

19. Yumani DF, Dungen FA, Weissenbruch MM. Incidence and risk factors for catheter-associated bloodstream infections in neonatal intensive care. Acta Paediatr. 2013;102(7):e293-e8. https://doi.org/10.1111/ apa.2013.102.issue-7

20. Foglia E, Meier MD, Elward A. Ventilator-associated pneumonia in neonatal and pediatric intensive care unit patients. Clin Microbiol Rev. 2007;20(3): 409-425. https://doi.org/10.1128/CMR.00041-06

21. Stapleton PJ, Murphy M, McCallion N, et al. Outbreaks of extended spectrum beta-lactamase-producing Enterobacteriaceae in neonatal intensive care units: a systematic review. Arch Dis Child Fetal Neonatal Ed. 2016;101(1):72-78. https://doi.org/10.1136/ archdischild-2015-308707

22. Moodley P, Coovadia YM, Sturm AW. Intravenous glucose preparation as the source of an outbreak of extended-spectrum $\beta$-lactamaseproducing Klebsiella pneumoniae infections in the neonatal unit of a regional hospital in KwaZulu-Natal: original article. S Afr Med J. 2005;95(11):861-864.

23. Sturm PA. Analysis of Klebsiella Outbreak in Neonatal Nursery at Mahatma Gandhi Memorial. Hosp. 2005;1-6.

24. Tekin $R$, Dal $T$, Pirinccioglu $H$, et al. A 4-year surveillance of deviceassociated nosocomial infections in a neonatal intensive care unit. Pediatr Neonatology. 2013;54(5):303-308. https://doi.org/10.1016/j. pedneo.2013.03.011

25. AlBasri SF, Shouib GM, Bajouh OS, et al. Maternal and neonatal outcomes in twin and triplet gestations in Western Saudi Arabia. Saudi Med J. 2017;38(6):657. https://doi.org/10.15537/smj.2017.6.17699

26. Brito DVD, Brito CSd, Resende DS, et al. Nosocomial infections in a Brazilian neonatal intensive care unit: a 4-year surveillance study. Rev Soc Bras Med Trop. 2010;43(6):633-637. https://doi.org/10.1590/ S0037-86822010000600006
27. Leal YA, Álvarez-Nemegyei J, Velázquez JR, et al. Risk factors and prognosis for neonatal sepsis in southeastern Mexico: analysis of a four-year historic cohort follow-up. BMC pregnancy childbirth. 2012;12(1): 48. https://doi.org/10.1186/1471-2393-12-48

28. Auriti $C$, Ronchetti MP, Pezzotti $P$, et al. Determinants of nosocomial infection in 6 neonatal intensive care units: an Italian multicenter prospective cohort study. Infect Control Hosp Epidemiol 2010;31(09):926-933. https://doi.org/10.1086/655461

29. Gebremedhin D, Berhe H, Gebrekirstos K. Risk Factors for Neonatal Sepsis in Public Hospitals of Mekelle City, North Ethiopia, 2015: Unmatched Case Control Study. PloS one. 2016;11(5): e0154798. https://doi.org/10.1371/journal.pone.0154798

30. Dal-Bó K, Silva RMd, Sakae TM. Nosocomial infections in a neonatal intensive care unit in South Brazil. Rev Bras Ter Intensiva. 2012;24(4):381-385. https://doi.org/10.1590/S0103507X2012000400015

31. Polin RA, Saiman L. Nosocomial infections in the neonatal intensive care unit. NeoReviews. 2003;4(3): e81-e9. https://doi.org/10.1542/ neo.4-3-e81

32. Kung $\mathrm{Y}-\mathrm{H}$, Hsieh $\mathrm{Y}-\mathrm{F}$, Weng $\mathrm{Y}-\mathrm{H}$, et al. Risk factors of late-onset neonatal sepsis in Taiwan: a matched case-control study. J Microbiol Immunol Infect. 2016;49(3):430-435. https://doi.org/10.1016/j. jmii.2013.10.001

33. Mahfouz A, Al-Azraqi T, Abbag F, et al. Nosocomial infections in a neonatal intensive care unit in south-western Saudi Arabia/Infections nosocomiales dans un service de soins intensifs néonatals du sudouest de l'Arabie saoudite. East Mediterr Health J. 2010;16(1):40.

34. Kasim K, El Sadak A-A, Zayed K, Abdel-Wahed A, Mosaad M. Nosocomial infections in a neonatal intensive care unit. Middle East $J$ Sci Res. 2014;19:1-7.

Received: 20-11-2017 Accepted: 14-03-2018 